\title{
LANGUAGE LEARNING IN CHINA
}

by Carl T. Erickson

One of the most awkward aspects of writing about China is the procurement of data. In August of this year I was a member of a study mission organized by Staten Island Community College to visit Peking, Shanghai, and Canton. To prepare for this trip, I enrolled in a "crash" course of Chinese in the Department of Modern Languages at SICC. The course was a happy blend of the "silent method" and pattern drills in our own language lab. If it did not give me fluency in Chinese, at least I could now recognize speech patterns. No longer did the language simply resemble a sing-song collection of sounds. Even the simple phrase "Ni hau ma?" (How are you'), made my job of filming a $16 \mathrm{~mm}$ color dccumentary of our mission much easier.

But if I experienced problems with the Chinese language, our interpreters had little difficulty with English, or indeed at least one other language. One of my first requests was to visit a language lab at the University of Peking. It soon became evident that this request would not be granted, especially when, on a stroll through the university grounds, the Modern Languages building was pointed out to me, but entrance was discouraged because of "repairs". This also occurred at Fukien University in Shanghai. Thus I had to rely on interview material gathered from our various interpreters.

The use of technological advances in education systems is not as well developed in China as it is in North America. The Rector of Peking University told me that they are constantly adding to their supply of equipment, especially motion picture projectors and tape recorders, but that they still had a long way to go before the supply would keep up with the demand. In the middle schools (which are the equivalent of our high schools), it is only very rarely that they have anything that approaches a language lab, and this usually consists of a record player or a tape recorder for a single classroom. In the universities, however, language labs form a very definite part of the instructional program. By our North American standards, these language labs would seem to be rather primitively furnished. In Peking University, one large room has been set aside to function as a language lab. The first rows have been built as carrels, equipped with a tape deck and a headset. The remaining five rows have headsets only. At the simple console at the front, there are a couple of tape recorders and a record player. The instructor can cornmunicate with the students in the carrels but not with those in the other positions. 
According to our interpreters the usual method of working in the lab is for the students to listen to a prose passage read to them with pauses for them to repeat what they have heard. Those students in the booths can record the lesson and their responses while the majority simply repeat aloud to the open air. Each student is required to spend at least one hour per week working in the lab. Additional work is encouraged and, according to our interpreters, is frequently carried out. This is done either in the lab with the equipment that is installed, or else in the dormitories with borrowed record players and tape recorders. For testing purposes the students record prose passages which are then graded by the instructor.

Patterned programs are not used for practice in structural drills. It would appear that, for the most part, the lab is used for pronunciation study and practice. The recorded material which the students hear is provided by native speakers but they are not professionals. For the most part, they are Frenchmein, Germans, or Englishmen who are of the same political bent as the Chinese and who now reside in Peking or Shanghai. The material they record is usually highly political in flavor and not at all representative of the oral language but rather of the written form. As in European educational systems, the pronunciations which the students learn are European: British English and Castilian Spanish. This source of speech models not only affects pronunciation but it also affects the vocabulary as well for the idioms which the interpreters used came from British English: "Hit it for six", "lorry", etc.

No mention was made of a special school for interpreters and in view of the youthfulness of many of our interpreters, it would seem that a proficiency in the language is all that is required to enter this field. Three whom we encountered were under twenty: two girls and a young man. All of them were quite fluent in English and all had had experience with language labs in their training at their universities. Our mission was assigned three interpreters in Canton who remained with us for the three weeks we were in China. The role of the interpreter is much more than that of helping to overcome the language barrier. When I began strolling at random with the $16 \mathrm{~mm}$ Arriflex I was very quickly assigned an interpreter of my own who stayed with me during our stay in Peking. In Shanghai, another interpreter was given this function. As an aside, it is interesting to note that with my own Super-8 camera I was quite free to roam at will.

In the various areas we visited (the Great Wall, a Cadre School, a commune), local interpreters would augment those assigned to us and relieve them if a speech became prolonged. The general quality of interpretation seemed to be quite high. Vocabulary did not seem to 


\section{Language Learning in China}

elude them, and the sentences flowed as normal speech. A young Chinese-American student with our group confirmed that the content was accurate.

The political atmosphere of China has seriously affected language learning in the universities. The Cultural Revolution of 1965-68 brought with it may reforms to the life style of intellectuals in China. One of these reforms was the necessity of spending an extensive period of time in the countryside laboring to produce food. This has created a severe problem in language learning where continuity is so necessary. Whenever this question was raised by our group it was either unanswered or vaguely alluded to. No precise explanation of how it was solved was ever received. Some reference was made to the fact that areas of higher learning are offered in factories and communes but my observations would indicate that these fields were primarily of a technological nature rather than liberal arts.

Within China itself language learning faces the problem of Romanization. Though the two main dialects of the language, Mandarin and Cantonese, offer difficulties of mutual comprehension, the written characters are universally understood. More and more, especially in Shanghai and Peking, the Roman alphabet is evident. Street signs bear the name of the street both in characters and in letters. In Shanghai in particular, a very large number of shops have the duplicate system of identification. At railroad stations, the name of the town is in both forms on the station platform. Literacy is increasing tremendously in today's China as young children are all taught to read and write characters. As time goes on they will eventually learn the alphabet. I was told that linguistic scholars are already trying to solve the problem of transferring the main dialects into mutually comprehensible Roman forms.

Whatever the weakresses of their methods of utilizing a language lab, the Chinese have produced speakers of foreign languages. Yet I came away with the feeling that with a more developed language lab program the quality of foreign language learning could be better in China.

ABOUT THE AUTHOR: Carl T. Erickson is Director of the Language Laboratory at Staten Island Community College in New York. 